\title{
Light Harvesting Schemes for High Efficiency Thin Film Silicon Solar Cells
}

\author{
Matthieu Despeisse, Mathieu Boccard, Corsin Battaglia, Gregory Bugnon, Mathieu Charrière, Loïc Garcia, \\ Maximilien Bonnet-Eymard, Jordi Escarre, Peter Cuony, Michael Stuckelberger, Gaetano Parascandolo, \\ Simon Hänni, Linus Löfgren, Jan-Willem Schüttauf, Laura Ding, Sylvain Nicolay, Fanny Meillaud and \\ Christophe Ballif
}

\author{
Ecole Polytechnique Fédérale de Lausanne (EPFL), Institute of Microengineering (IMT), Laboratory of \\ Photovoltaics and Thin Film Electronics, 2000 Neuchâtel, Switzerland
}

\begin{abstract}
In Thin Film Silicon (TF-Si) solar cells light harvesting schemes must guarantee an efficient light trapping in the thin absorber layers without decreasing the silicon layers quality and consecutively the $p$-i-n diodes electrical performance. TF-Si solar cells resilience to the substrate roughness is reported to be possibly improved through optimizations of the cell design and of the silicon deposition processes. By further tailoring the superstrate texture, amorphous silicon / microcrystalline silicon

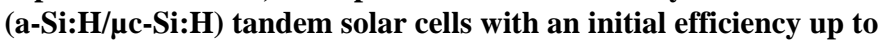
$13.7 \%$ and a stabilized efficiency up to $11.8 \%$ are demonstrated on single-scale textured superstrates. An alternative approach combining large and smooth features nanoimprinted onto a transparent lacquer with small and sharp textures from asgrown LPCVD ZnO is then shown to have a high potential for further increasing TF-Si devices efficiency. First results demonstrate up to $14.1 \%$ initial efficiency for a TF-Si tandem solar cell.
\end{abstract}

Index Terms - thin film, amorphous silicon, light trapping, photovoltaic cells, silicon, tandem cells.

\section{INTRODUCTION}

To further enhance the potential of Thin Film Silicon (TFSi) photovoltaic technology, efficient light harvesting schemes are essential to maximize absorption in the thin absorber layers. Most importantly, all optical performance optimization must be realized without negatively impacting the electrical performances of the $\mathrm{p}-\mathrm{i}-\mathrm{n}$ junctions. Parasitic absorptions in the electrodes and doped layers have to be minimized while still ensuring sufficient conduction. In that respect, progress realized in our laboratory with the development of mixed phase doped silicon rich silicon oxide materials is detailed in section II, while the implementation of a high mobility transparent conductive oxide in combination with a transparent textured superstrate realized by nanoimprinting is detailed in section IV. In order to then efficiently trap light in the thin absorber layers, light scattering at rough interfaces is usually used and is typically introduced by utilizing surfacetextured substrates. However, it was also reported that TF-Si layers deposited on highly textured substrates can exhibit locally low quality material regions or $2 \mathrm{D}$ nano-porous phases, which lead to deterioration of the electrical performance of TF-Si p-i-n junctions [1-7]. To maximize TF-
Si devices efficiency, one has therefore to find the optimum trade-off between high electrical and optical performances. This trade-off is first reported in section II to be possibly optimized by the development of cell design techniques and silicon deposition processes which improve TF-Si solar cell resilience to the substrate roughness, allowing retaining high electrical performance on rougher substrates [1, 5-6]. Then, the morphology of the superstrate texture can be adapted to provide an efficient light scattering without exhibiting too sharp features, so as to ensure high quality silicon films [7]. Best amorphous silicon / microcrystalline silicon (a-Si:H/ $\mu \mathrm{c}-$ $\mathrm{Si}: \mathrm{H})$ micromorph tandem solar cells obtained so far on single-layer textured superstrates made of plasma treated $\mathrm{ZnO}$ grown by low-pressure chemical vapor deposition (LPCVD) are reported in section III.

Alternative approaches to the standard single-scale textured electrode superstrates are finally described in section IV. Conduction, transparency and texture requirements of TF$\mathrm{Si}$ superstrates can be possibly decoupled via a multi-layer approach. A highly transparent TCO layer can ensure conduction with no restriction on its texture, while light scattering is achieved with a textured surface realized with a highly transparent medium. In that way, conduction transparency optimization of the TCO is decoupled from the texture morphology optimization. Then, multi-scale texturing is reported: it was developed to provide efficient light incoupling and light scattering over the full spectral range while enabling morphologies adapted for the growth of high quality $\mu \mathrm{c}-\mathrm{Si}: \mathrm{H}$ material and therefore for high electrical performance TF-Si devices [8]. Following such approach, a tandem device with an initial efficiency surpassing $14 \%$ is reported.

\section{CELL ARCHITECTURE AND PECVD PROCESS CONDITIONS FOR TEXTURED SUBSTRATES}

Doped nano-structured silicon rich silicon oxide layers were synthesized by PECVD from a gas mixture of silane $\left(\mathrm{SiH}_{4}\right)$, hydrogen, of an oxygen precursor $\left(\mathrm{CO}_{2}\right.$ in this study) 
and of phosphine $\left(\mathrm{PH}_{3}\right)$ or tri-methyl boron $\left(\mathrm{B}\left(\mathrm{CH}_{3}\right)_{3}\right)$ respectively for n-type and p-type doping. Optimization of the PECVD processes permitted a clear phase separation in the developed layers, with the creation of silicon nano-filaments elongated in the growth direction, embedded in a silicon oxide matrix [9], as shown in the energy-filtered TEM image of Figure 1. For the prepared mixed-phase material, a high ntype doping ratio $\mathrm{PH}_{3} /\left(\mathrm{PH}_{3}+\mathrm{SiH}_{4}\right)$ of up to $5 \%$ could be realized without impacting the crystalline volume fraction or the nano-structure of the silicon rich phase. For such n-type films, layers with a refractive index down to 1.7 at a wavelength of $600 \mathrm{~nm}$ were successfully implemented in cells. For p-type doping of the developed silicon rich silicon oxide materials, optical and electrical performances are detailed in [10]. The p-type doping ratio $\mathrm{B}\left(\mathrm{CH}_{3}\right)_{3} /\left(\mathrm{B}\left(\mathrm{CH}_{3}\right)_{3}+\mathrm{SiH}_{4}\right)$ is here limited to about $0.5 \%$. A higher $\mathrm{B}\left(\mathrm{CH}_{3}\right)_{3}$ concentration is then shown to affect the crystalline volume fraction of the $\mathrm{Si}$ phase [10], consecutively reducing the layer conductivity. In comparison to n-type doping, $\mathrm{p}$-type layers with a minimum refractive index of about 2.5 can therefore be developed with sufficient transverse conductivity to be integrated in cell. For both doping types and both a-Si:H and $\mu \mathrm{c}-\mathrm{Si}: \mathrm{H}$ junctions, the optimum oxide layers integrated in the cells detailed in the following correspond to layers with a maximum oxygen content (i.e. maximum $\mathrm{CO}_{2} / \mathrm{SiH}_{4}$ gas flux ratio) while keeping a sufficient transverse conductivity to not impact the cell electrical performance.

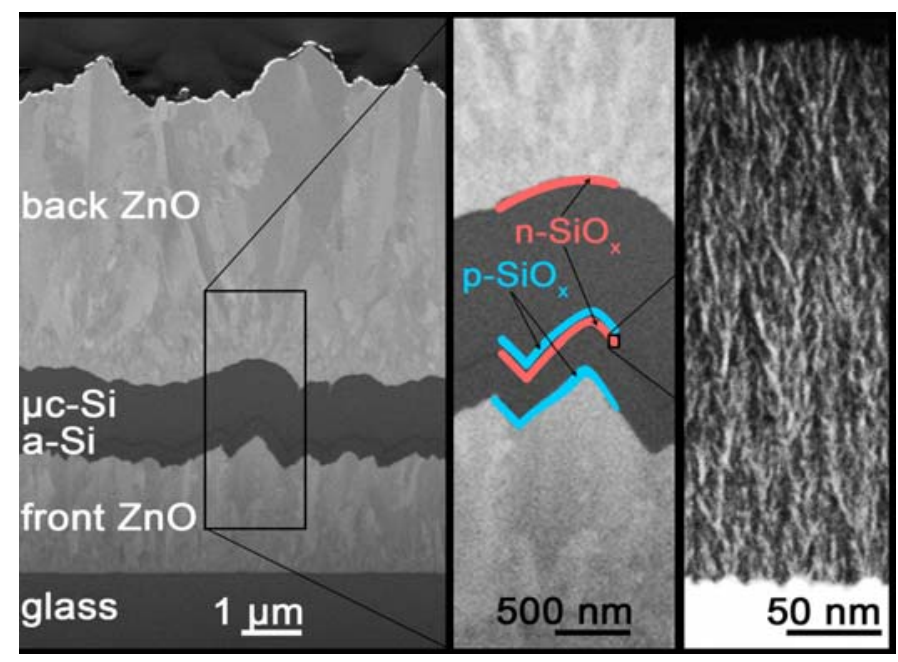

Fig. 1. Left: SEM image of a FIB cross section of an a-Si:H/ $\mu \mathrm{c}-$ $\mathrm{Si}: \mathrm{H}$ tandem cell with $\mathrm{ZnO}$ front and back electrodes. Middle: zoom in the SEM image to illustrate the implementation of p-type and ntype doped silicon rich silicon oxide layers in both top and bottom cell. Right: EFTEM image of a n-type doped silicon rich silicon oxide layer exhibiting a semiconducting silicon filament nanostructure embedded a highly transparent silicon oxide matrix: white contrast regions correspond to silicon rich phase, dark contrast region to silicon oxide rich phase (right, [9]).

The implementations of both n-type and p-type silicon rich silicon oxide layers in thin film silicon solar cells permit to:
- Improve the light management [9-14]: transparent intermediate reflector layer in micromorph solar cells and reduced parasitic absorption (for instance highly transparent window layer).

- Increase electrical performance and cell resilience to the substrate texture [1, 5-6]: electrical performance gain scales with substrate roughness, and up to $6 \%$ and $20 \%$ gains were demonstrated respectively for a-Si:H and $\mu \mathrm{c}-$ Si:H p-i-n junctions [1].

Silicon oxide doped layers therefore not only improve the cell optical performance but were demonstrated to also mitigate the impact of the local low quality material regions onto the cell electrical properties $[1,15]$. The implementations of these layers both for a-Si:H and $\mu \mathrm{c}-\mathrm{Si}: \mathrm{H}$ p-i-n junctions thus permits the integration of rougher superstrates: these doped layers are integrated both in the top and bottom cells of the tandem cells presented in next sections (configuration as shown in Figure 1).

In addition, it was recently demonstrated that plasmaenhanced chemical vapor deposition (PECVD) process conditions of silicon layers have to be optimized not only to provide a high bulk material quality but also to reduce the density and/or to increase the quality of the local defective material regions which typically grow on high angle V-shaped valleys of the substrate texture $[1,5]$. Some PECVD processes can lead to films with low bulk defect density, but with strongly defectives localized areas near cracks. It must therefore be emphasized that for a given plasma process, the global material quality and the resulting cell electrical properties will strongly depend on the substrate texture. Optimum plasma conditions will therefore depend on the exact morphology on which the film is grown.

The implementation of silicon oxide doped layers combined with PECVD processing conditions which can provide a dense absorber layer with reduced local defective regions creation recently permitted to reach an unprecedented $\mu \mathrm{c}-\mathrm{Si}: \mathrm{H}$ single junction solar cell efficiency of $10.9 \%$ (for a cell area of $0.5 \times 0.5 \mathrm{~mm}^{2}$ ), as realized in two different reactors in our laboratory [5-6].

\section{MICROMORPH TANDEM CELL ON LPCVD ZNO}

TF-Si micromorph tandem solar cells were first optimized for single-layer textured electrodes. $\mathrm{ZnO}$ grown by LPCVD provides as-grown pyramidal features exhibiting excellent light scattering properties. Even in the case of optimized TF$\mathrm{Si}$ tandem solar cells using doped layers and PECVD processes as described in section II, sharp features of LPCVD $\mathrm{ZnO}$ texture are still detrimental to the cell electrical properties, mainly for $\mathrm{ZnO}$ layers with a thickness above 1.2 $\mu \mathrm{m}$, i.e. for substrate feature sizes with peak to peak height above $300 \mathrm{~nm}$ and mean angle of surface incidence above 35 
degrees. For larger feature sizes (thicker $\mathrm{ZnO}$ layers), a plasma treatment of the electrode surface can smoothen the most pronounced $\mathrm{V}$-shaped valleys of the texture and allow to recover high silicon layers quality (reduced local nano-porous regions) and high cell electrical properties, at the possible price of reduced light in-coupling and scattering [7]. An optimum $\mathrm{ZnO}$ surface could therefore be determined for our a-Si:H/ $\mu \mathrm{c}-\mathrm{Si}: \mathrm{H}$ tandem solar cell design: it has a typical thickness of 2 to $3 \mu \mathrm{m}$ and a soft plasma treatment of the surface [7]. Its typical surface texture is shown in Figure 2.

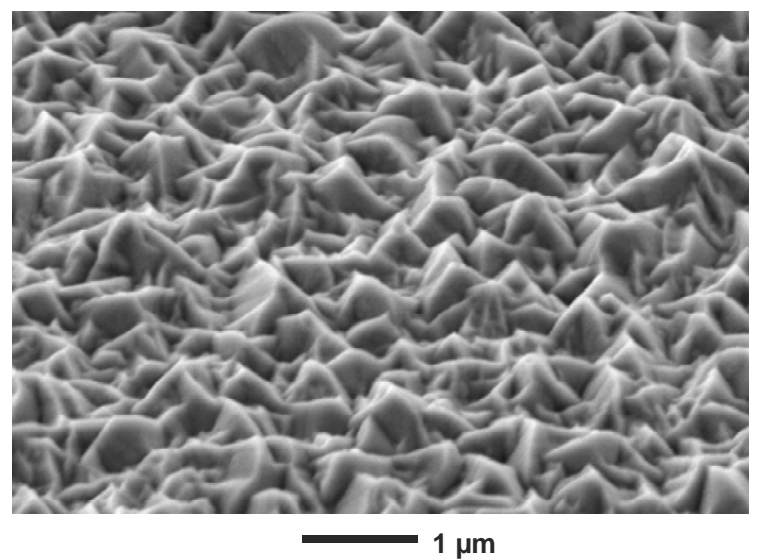

Fig. 2. SEM image of a tilted top surface of an optimum LPCVD $\mathrm{ZnO}$ front electrode: $\sim 2.5 \mu \mathrm{m}$ thick layer with a soft plasma treatment.

Tandem cells were optimized on such substrate: they implement a $250 \mathrm{~nm}$ thick a-Si:H top cell, a $50 \mathrm{~nm}$ thick silicon rich silicon oxide intermediate reflecting layer (IRL), a $1.4 \mu \mathrm{m}$ thick $\mu \mathrm{c}-\mathrm{Si}: \mathrm{H}$ bottom cell, a LPCVD $\mathrm{ZnO}$ back electrode and a dielectric white back reflector. All Si layers were deposited in KAI reactor types. The external quantum efficiency (EQE) and the corresponding short circuit current densities $\left(\mathrm{J}_{\mathrm{SC}}\right)$ obtained with these devices in the top and bottom cells are shown in Figure 3 and described in Table I.

To further increase the light in-coupling, micrometric random square based pyramids were imprinted on a lacquer disposed at the air/glass interface. The application of this anti-reflective coating (ARC) described in [16] is shown to yield $5.8 \%$ and $2.5 \%$ relative $\mathrm{J}_{\mathrm{SC}}$ increase respectively in the top and bottom cells ( $\sim 4 \%$ gain in total current). The pyramids morphology permits to reduce primary reflection losses via double rebound of the incoming light at the glass surface. In addition, possible anti-escaping effect and slight light diffusion result in a small improvement also in light trapping in the device, as described in [16]. Overall, combining the optimized $\mathrm{ZnO}$ superstrate and cell design with the micrometric texture at the air/glass interface permits to achieve a high total $\mathrm{J}_{\mathrm{SC}}$ of $27 \mathrm{~mA} / \mathrm{cm}^{2}$ in the developed tandem device, even for a bottom cell thickness of $1.4 \mu \mathrm{m}$. Most importantly, high optical performance is realized while maintaining high electrical performance, as detailed in Table I. A high initial efficiency of $13.7 \%$ is consecutively realized for a reasonably thick device (total $\mathrm{Si}$ layers thickness $<1.7 \mu \mathrm{m})$. This solar cell current matching condition was not optimum: the tandem cell is in a top limitation case after 1000 hours of light induced degradation under a class A 1 sun illumination at $50{ }^{\circ} \mathrm{C}$. Still, a stabilized efficiency of $11.8 \%$ was achieved with such device, demonstrating that stabilized efficiency approaching $12 \%$ can certainly be realized with the use of single-layer LPCVD $\mathrm{ZnO}$ front and back electrodes and with a reasonable thickness of Si layers deposited in KAI reactors.

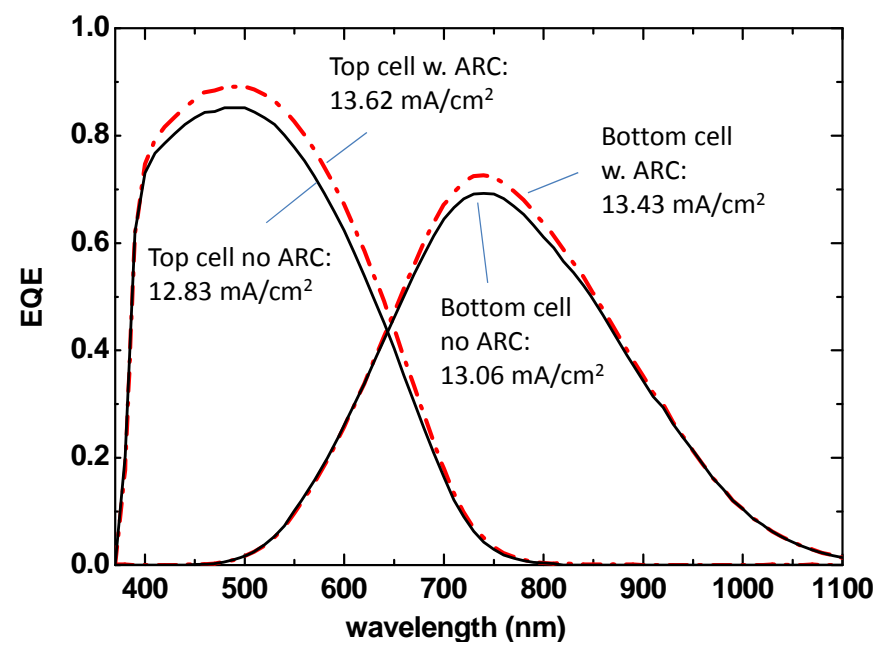

Fig. 3. External Quantum Efficiency (EQE) curves of a $250 \mathrm{~nm}$ thick a-Si:H top cell and a $1.3 \mu \mathrm{m}$ thick $\mu \mathrm{c}-\mathrm{Si}: \mathrm{H}$ bottom cell implemented in a micromorph tandem solar cell deposited on a LPCVD $\mathrm{ZnO}$ single scale textured substrate and integrating a $60 \mathrm{~nm}$ thick silicon oxide intermediate reflecting layer.

TABLE I. Solar cell performance of $1 \mathrm{~cm}^{2}$ a-Si:H/ $\mu \mathrm{c}-\mathrm{Si}: \mathrm{H}$ TF-Si tandem solar cells implementing LPCVD $\mathrm{ZnO}$ front and back electrodes, $250 \mathrm{~nm}$ a-Si:H top cell, $50 \mathrm{~nm}$ IRL and a $1.4 \mu \mathrm{m} \mu \mathrm{c}-\mathrm{Si}: \mathrm{H}$ bottom cell.

\begin{tabular}{lccccc}
\hline & $\begin{array}{c}\mathrm{J}_{\mathrm{SC} \text { top }} \\
\left(\mathrm{mA} / \mathrm{cm}^{2}\right)\end{array}$ & $\begin{array}{c}\mathrm{J}_{\mathrm{SC} \text { bottom }} \\
\left(\mathrm{mA} / \mathrm{cm}^{2}\right)\end{array}$ & $\begin{array}{c}\mathrm{V}_{\mathrm{OC}} \\
(\mathrm{V})\end{array}$ & $\begin{array}{c}\mathrm{FF} \\
(\%)\end{array}$ & $\begin{array}{c}\text { Eff. } \\
(\%)\end{array}$ \\
\hline Initial state no ARC & 12.85 & 13.06 & 1.395 & 72.5 & 13 \\
\hline $\begin{array}{l}\text { Initial state w. ARC } \\
\text { Stabilized state after }\end{array}$ & 13.6 & 13.4 & 1.395 & 73.5 & 13.7 \\
\hline \begin{tabular}{l}
1000 h LID, w. ARC \\
\hline
\end{tabular} & & 13.3 & 1.36 & 66.4 & 11.8 \\
\hline
\end{tabular}

\section{MULTI-SCALE SUPERSTRATES}

Textures employed in TF-Si solar cells to provide an efficient light-trapping are generally dictated by the underlying growth and etching kinetics of the textured transparent conductive oxide (TCO) and/or glass. We recently 
developed transparent electrodes with arbitrary surface morphologies by using ultraviolet nano-imprinting lithography (UV-NIL) to replicate an arbitrary structure made from a transparent or opaque arbitrary master material [1718]. The textured nanoimprinted lacquer can then be combined with a thin and highly transparent hydrogen doped indium oxide $\mathrm{In}_{2} \mathrm{O}_{3}: \mathrm{H}(\mathrm{IOH})$ TCO layer [18-19]. The efficient light scattering properties of the textured transparent lacquer combined with the high transparency and conductivity of $\mathrm{IOH}$ were shown to result in a high total current of $26 \mathrm{~mA} / \mathrm{cm}^{2}$ in a micromorph cell using a thin $\mu \mathrm{c}-\mathrm{Si} . \mathrm{H}$ bottom cell $(1.1 \mu \mathrm{m})$ and no AR coating [18]. This approach shows a high potential as the texture is free from morphological growth constraints, while the employed TCO guarantees a high transparency [1819]. These developments can then be combined with LPCVD $\mathrm{ZnO}$ electrodes to build nano-scale to micro-scale multitextured superstrates. The objectives following such approach are to provide efficient light in-coupling and light scattering over the full spectral range with different texture scales [2021] while enabling morphologies adapted for $\mu \mathrm{c}-\mathrm{Si}: \mathrm{H}$ cell growth [8]. Large and smooth LPCVD $\mathrm{ZnO}$ pyramids were replicated by UV-NIL and combined with a thin and highly transparent $\mathrm{IOH}$ layer to provide conduction. Finally a thin non-intentionally doped LPCVD ZnO layer was deposited to add small and sharp pyramidal features to the superstrate morphology. The obtained surface morphology is shown in Figure 4.

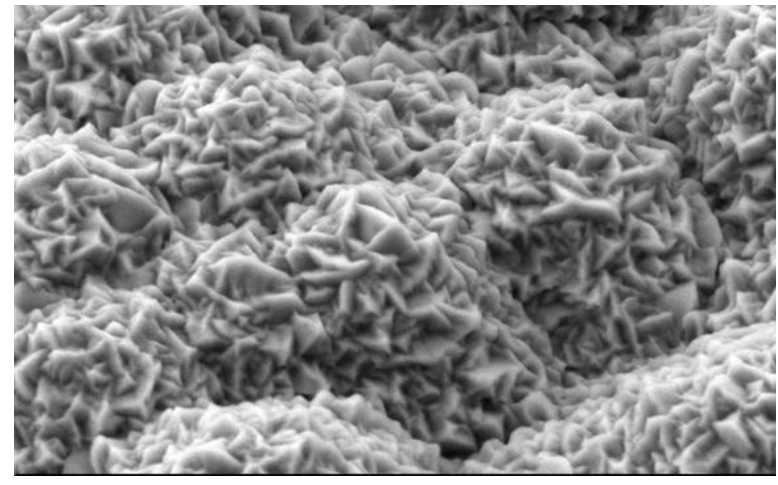

Fig. 4. Top: SEM image of a tilted top surface of a multi-scale superstrate implementing large understructures covered with small and sharp features of a thin LPCVD ZnO layer.

When used as front electrode for a micromorph cell with respective top cell, intermediate reflective layer (IRL) and bottom cell thicknesses of $260 \mathrm{~nm}, 50 \mathrm{~nm}$ and $2.4 \mu \mathrm{m}$, a very high total current density of $28.3 \mathrm{~mA} / \mathrm{cm}^{2}$ was reached. Similar micromorph solar cells were deposited directly on an $\mathrm{IOH}$ - thin LPCVD $\mathrm{ZnO}$ stack, and on a flat IOH layer directly on a flat glass.

The thin LPCVD ZnO layer is first shown to allow for a clear current gain in the top cell with almost $2 \mathrm{~mA} / \mathrm{cm}^{2}$ gain with respect to the flat $\mathrm{IOH}$ electrode case. The small sharp pyramidal features are confirmed to provide an efficient light in-coupling and trapping for the top cell, while still allowing for the growth of high quality $\mu \mathrm{c}-\mathrm{Si}: \mathrm{H}$ bottom cell, so that only $10 \mathrm{mV}$ of $\mathrm{V}_{\mathrm{OC}}$ is lost in comparison to the electrically ideal flat electrode case. However, current is not sufficient in the bottom cell. This limitation is then solved by adding the large and smooth features understructure in the multi-scale approach: high top cell current is conserved thanks to the small and sharp features of the thin LPCVD $\mathrm{ZnO}$ layer, while the bottom cell light trapping is boosted by the large features understructure, resulting in up to $1.4 \mathrm{~mA} / \mathrm{cm}^{2}$ current gain in the bottom cell in comparison to the IOH - thin LPCVD $\mathrm{ZnO}$ electrode. Here again, a high $\mathrm{V}_{\mathrm{OC}}$ of $1.41 \mathrm{~V}$ is conserved $(20 \mathrm{mV}$ loss in comparison to the flat electrode electrical ideal case), demonstrating that the two structures employed to realize an efficient light trapping in both subcells are adapted for the growth of high quality silicon layers. Overall, an initial efficiency of $14.1 \%$ is demonstrated for a thin film silicon tandem solar cell following the presented multi-scale approach.

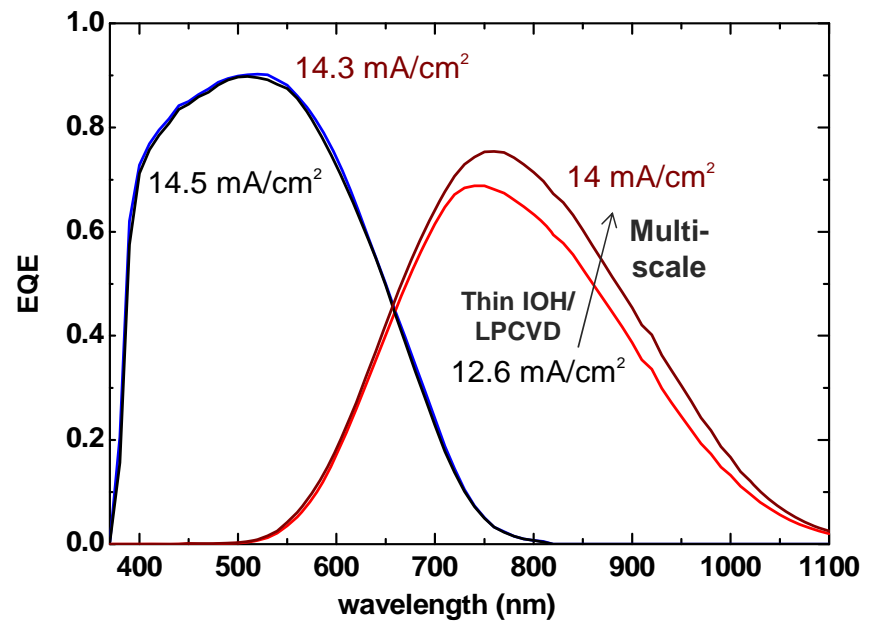

Fig. 5. External Quantum Efficiency (EQE) curves of micromorph tandem solar cell deposited on a IOH - thin LPCVD ZnO superstrate and on a multi-scale superstrate.

TABLE II. Initial state solar cell performance of $1 \mathrm{~cm}^{2} \mathrm{a}-\mathrm{Si}: \mathrm{H} / \mu \mathrm{c}-$ $\mathrm{Si}: \mathrm{H}$ TF-Si tandem solar cells on various substrates (all cells have an ARC on the glass as described in [16]).

\begin{tabular}{lccccc}
\hline & $\begin{array}{c}\mathrm{J}_{\mathrm{SC} \text { top }} \\
\left(\mathrm{mA} / \mathrm{cm}^{2}\right)\end{array}$ & $\begin{array}{c}\mathrm{J}_{\mathrm{SC} \text { bottom }}\left(\mathrm{mA} / \mathrm{cm}^{2}\right) \\
\text { Flat IOH }\end{array}$ & $\begin{array}{c}\mathrm{V}_{\mathrm{OC}} \\
(\mathrm{V})\end{array}$ & $\begin{array}{c}\mathrm{FF} \\
(\%)\end{array}$ & $\begin{array}{c}\text { Eff. } \\
(\%)\end{array}$ \\
\hline IOH + thin LPCVD ZnO & 14.6 & 11.0 & 1.432 & 71.8 & 11.3 \\
\hline $\begin{array}{l}\text { Nanoimprinted under- } \\
\text { structure + IOH + thin }\end{array}$ & 14.3 & 14 & 1.42 & 75 & 13.4 \\
\begin{tabular}{l} 
LPCVD ZnO: multi-scale \\
\hline
\end{tabular} & & & & & \\
\hline
\end{tabular}




\section{CONCLUSION}

High efficiency thin film silicon solar cells could be developed by optimizing the trade-off between optical and electrical performances. Advanced nanomaterials (silicon rich silicon oxide mixed phase layers) and PECVD processes optimized for dense $\mu \mathrm{c}-\mathrm{Si}: \mathrm{H}$ with a high bulk quality were shown to allow for up to $13.7 \%$ initial efficiency and $11.8 \%$ stabilized efficiency for TF-Si tandem solar cells deposited on an optimum LPCVD $\mathrm{ZnO}$ electrode. Advanced superstrate concept comprising large and smooth understructure guaranteeing light trapping for the bottom cell and small and sharp surface features leading to high light in-coupling and light trapping in the top cell was shown to have a high potential to realize an efficient light trapping while conserving high electrical performance. First results demonstrate a very high efficiency tandem solar cell with an initial efficiency of $14.1 \%$ based on this concept.

\section{ACKNOWLEDGEMENT}

This work was supported by the EU FP7 project Fast-Track and by the Swiss Federal Office for Energy (OFEN).

\section{REFERENCES}

[1] M. Despeisse, G. Bugnon, C. Battaglia et al., "Optimization of thin film silicon solar cells on highly textured substrate", Physica Stat. Solidi (a), 2011, Vol. 208 (4) pp. 1863-1868.

[2] H. Sai, Y. Kanamori, M. Kondo, "Flattened light-scattering substrate in thin film silicon solar cells for imporved infrared response", APL 2011, Vol. 98 (11), p. 113502.

[3] T. Matsui, M. Tsukiji, H. Saika, T. Toyama, and H. Okamoto, "Influence of substrate texture on microstructure and photovoltaic performances of thin film polycrystalline silicon solar cells", Journal of non-cryst. Solids 2002, Vol. 299-302, pp. 1152-1156.

[4] H. Li , R.H. Franken, J.K Rath, R.E.I Schropp, "Structural defects caused by a rough substrate and their influence on the performance of hydrogenated nano-crystalline silicon n-i-p solar cells", Solar Energy Materials \& solar cells, 93, 338 (2009).

[5] G. Bugnon, G. Parascandolo, T. Söderström et al., "A new view of Microcrystalline silicon: The role of plasma processing in achieving a dense and stable absorber material for photovoltaic applications", Advanced Functional Materials, 2012, DOI: 10.1002/adfm.201200299

[6] S. Hänni, D.T.L. Alexander, L. Ding et al., "On the interplay between material quality and interfaces in high efficiency microcrystalline silicon solar cells", in $38^{\text {th }}$ IEEE Photovoltaic Specialist Conference, 2012.
[7] M. Boccard, T. Söderström, P. Cuony et al., "Optimization of $\mathrm{ZnO}$ front electrodes for high efficiency micromorph thin film silicon solar cells", IEEE JPV, 2012, DOI: 10.1109/JPHOTOV.2011.2180514.

[8] M. Boccard, C. Battaglia, S. Hänni et al., "Multiscale Transparent Electrode Architecture for Efficient Light Management and Carrier Collection in Solar Cells", Nanoletters 2012, Vol. 12 (3), pp. 1344-1348.

[9] P. Cuony, D.T.L. Alexander, M. Despeisse, et al., « Silicon filaments in silicon oxide for next generation photovoltaics ", Advanced Materials, 2012, Vol. 24 (9), pp. 1182-1186.

[10] P. Cuony, M. Marending, M Boccard et al., "p-type silicon oxide layer and its different functionalities in thin-film microcrystalline silicon solar cells", APL, 2010, Vol. 97, 213502.

[11] A. Lambertz, T. Grundler and F. Finger, "Hydrogenated amorphous silicon oxide containing a microcrystalline silicon phase and usage as an intermediate reflector in thin-film silicon solar cells", J. Appl. Phys., 2011, Vol. 109, 113109.

[12] K. Yamamoto, A. Nakajima, M. Yoshimi et al., "A thin film silicon solar cell and module", Progress in Photovoltaics, 2005, Vol. 13 (6), pp. 489-494.

[13] P. Delli Veneri, L. V. Mercaldo and L. Usatii, "Improved micromorph solar cells by means of mixed-phase n-doped silicon oxide layers", Progress in Photovoltaics, 2011, 97, 023512 (2010).

[14] T. Krajangsang, S. Kasashima, I.A. Yunaz et al., "Effect of p$\mu \mathrm{c}-\mathrm{Si}-\mathrm{O}: \mathrm{H}$ layer on performance of hetero-junction microcrystalline silicon solar cells", Current Applied Physics, 2010, Vol. 10 (3), pp. S357-S360.

[15] M. Despeisse, G. Bugnon, A. Feltrin, "Resistive interlayer for improved performance of thin film silicon solar cells on highly textured substrates", APL, 2010, Vol. 96, p. 073507.

[16] J. Escarre, K. Söderström, M. Despeisse et al., « Geometric Light Trapping for high efficiency thin film silicon solar cells ", Solar Energy Mat. and Solar Cells, 2012, Vol. 98, pp. 185-190.

[17] J. Escarre, K. Söderström, C. Battaglia, "High fidelity transfer of nanometric random textures by UV embossing for thin film solar cells applications", Solar Energy Materials and Solar Cells 2011, Vol. 95, pp. 881-886.

[18] C. Battaglia, J. Escarre, K. Söderström, "Nanoimprint lithography for high efficiency thin film silicon solar cells", Nanoletters 2011, Vol. 11, p. 661.

[19] T. Koida, H. Sai and M. Kondo, "Application of hydrogen doped $\mathrm{In}_{2} \mathrm{O}_{3}$ transparent conductive oxide to thin film microcrystalline silicon solar cells", Thin Solid Films, 2010, Vol. 518, pp. 2930-2933.

[20] F. Toor, H.M. Branz, M. R. Page et al., « Multi-scale surface texture to improve blue response of nanoporous black silicon solar cells », APL, 2011, Vol. 99, p. 103501.

[21] O. Isabella, J. Krc, M. Zeman, "Modulated surface textures for enhanced light trapping in thin-film silicon solar cells", APL, Vol. 97, p. 101106. 